\title{
KUALITAS KAKAO BUBUK DIPASARAN KOTA MAKASSAR
}

\author{
Quality of Cocoa Powder In City Of Makassar \\ ${ }^{1}$ Khaerunnisa dan ${ }^{2}$ Endang Sri Rejeki \\ Balai Besar Industri Hasil Perkebunan Makassar
}

Jl. Prof. Dr. Abdurahman Basalamah No.28. Makassar 90231. Indonesia

Email : khaerunnisahendra@yahoo.com dan ichimatesan@gmail.com

\begin{abstract}
ABSTRAK. Kakao merupakan salah satu hasil perkebunan yang dapat memberikan kontribusi untuk peningkatan devisa Indonesia. Salah satu produk hilir dari biji kakao adalah bubuk kakao, yang kemudian dapat diolah menjadi beberapa produk yang bernilai ekonomi tinggi. Kakao bubuk adalah produk dari biji kakao yang diperoleh dari bungkil kakao yang diubah bentuknya menjadi bubuk.Kakao bubuk sebagai salah satu produk olahan biji kakao yang sangat di minati para industri.. Tujuan penelitian yaitu untuk mengetahui mutu dari kakao bubuk yang beredar dipasaran kota makassar. Metode penelitian ini adalah metode survey deskreptif yang bertujuan menggambarkan parameter parameter penting yang terdapat dalam bubuk kakao yang beredar di Makassar. Berdasarkan hasil survey data uji kadar air, kadar lemak, kadar kehaluaan dan cemaran logam pada kakao bubuk dari 15 sample kakao bubuk yang ada dipasaran kota Makassar dapat disimpulkan bahwa dari 15 sample yang ada, rata - rata ada yang sudah memenuhi standar SNI tetapi pada kadar air masih terdapat 2 sample dengan kadar air yang melebihi standar mutu, akan tetapi bila dilihat kadar lemaknya masih dapat dikatakan bahwa rata-rata industri yang ada dikota Makassar masih dalam taraf kualitas yang baik.
\end{abstract}

Kata Kunci : biji kakao, kakao bubuk, survey, data, mutu.

ABSTRACT. Cocoa is one of the plantation products that can contribute to increasing Indonesia's foreign exchange. One of the downstream products from cocoa beans is cocoa powder, which can then be processed into several products of high economic value. Cocoa powder is a product of cocoa beans that is obtained from cocoa cake which is transformed into powder. Cocoa powder is one of the processed cocoa beans products that are very interested in the industry. The purpose of the research is to determine the quality of powdered cocoa that is marketed in Makassar. The method of this research is a descriptive survey method which aims to describe important parameter parameters contained in cocoa powder circulating in Makassar. Based on the results of a survey of moisture content, fat content, aging content and metal contamination in powdered cocoa from 15 powdered cacao samples in the market in Makassar, it can be concluded that out of the 15 samples, on average there were those who met SNI standards but at levels there are still 2 samples with water content that exceeds the quality standard, but if you look at the fat content it can still be said that the industry average in the city of Makassar is still in good quality.

Keywords : cocoa beans, cocoa powder, survey, data, quality.

\section{PENDAHULUAN}

Kakao merupakan salah satu hasil perkebunan yang dapat memberikan kontribusi untuk peningkatan devisa Indonesia. Perkembangan area tanaman kakao rakyat yang cukup pesat di Indonesia perlu di dukung dengan kesiapan sarana dan metode pengolahan yang cocok untuk petani agar mereka mampu menghasilkan biji kakao dengan mutu seperti yang dipersyaratkan oleh Standar Nasional Indonesia (SNI,2008). Salah satu produk hilir dari biji kakao 
adalah bubuk kakao, yang kemudian dapat diolah menjadi beberapa produk yang bernilai ekonomi tinggi.

Mutu biji kakao yang dihasilkan oleh petani kakao Indonesia sangat rendah karena kurangnya fermentasi, tidak cukup kering, keasaman tinggi, cita rasa sangat beragam, akibatnya harga biji kakao relatif rendah.sehingga banyak produsen biji kakao membuat produk bubuk kakao dengan berbagai metode. Salah satu cara untuk mendapatkan warna dan rasa kakao bubuk yang lebih baik adalah melalui proses alkalisasi (Beckett, 1999).

Kakao bubuk adalah produk dari biji kakao yang diperoleh dari bungkil kakao yang diubah bentuknya menjadi bubuk (SNI, 2009). Bubuk kakao berkadar lemak lebih tinggi biasanya memiliki warna lebih gelap dengan flavor yang lebih ringan. Bubuk kakao umumnya digunakan dalam berbagai produk pangan seperti minuman cokelat, ingredient untuk cake, pudding, ice cream, dan sebaganiya (Abraham, 1982).

Kakao bubuk sebagai salah satu produk olahan biji kakao yang sangat di minati para industri. Cokelat bubuk atau kakao bubuk terbuat dari bungkil atau ampas biji cokelat yang telah dipisahkan dari lemak cokelatnya. Bungkil ini dikeringkan dan digiling halus sehingga terbentuk tepung cokelat atau bubuk cokelat. Terdapat 2 jenis cokelat bubuk yaitu melalui proses natural (non alkalized cocoa powder) dan yang kedua melalui proses Dutch (alkalized cocoa powder). Untuk bubuk cokelat atau natural cocoa powder memiliki warna lebih terang sedangkan yang Dutch cocoa powder memiliki warna lebih gelap. Kebanyakan coklat bubuk atau kakao bubuk yang dijual dipasaran adalah jenis natural cocoa powder. Cokelat bubuk natural dibuat dari bubur cokelat atau balok cokelat pahit, dengan menghilangkan sebagian besar lemaknya hingga tinggal 18- $23 \%$. (Susanti, 2012).

Dari segi kesehatan, bubuk kakao sangat bermanfaat bagi tubuh karena cokelat kaya akan kandungan antioksidan yaitu fenoldon dan flavonoid yang dapat meningkatkan system kekebalan tubuh. Bubuk cokelat mengandung 12 kalori, serat kasar 4 persen, zat besi $7 \%$, magnesium sebesar $10 \%$. Selain itu ada studi lain yang menunjukkan bahwa kakao bubuk memiliki efek positif terhadap kesehatan kulit wajah (Majalah Indonesia, 2017).

Permasalahan yang dihadapi para pelaku industri kakao bubuk di Indonesia khususnya daerah Sulawesi selatan (Makassar), yaitu masih tingginya kadar lemak kakao bubuk dan kualitas warna kakao bubuk yang belum sebanding dengan produk impor, sehingga kualitas kakao bubuk yang beredar dipasaran belum diketahui secara pasti kualitasnya.(Mulato.et, al. 2005). Untuk mengetahui mutu dari kakao bubuk yang dihasilkan oleh industri pengolah kakao bubuk, maka perlu dilakukan analisa kualitas atau mutu dari kakao bubuk yang dihasilkan dengan melakukan pengujian laboratorium dengan parameter yang sesuai dalam SNI Kakao Bubuk.. Sehingga dengan melihat hasil mutu kakao bubuk, dapat diketahui kualitas kakao bubuk yang sesuai dengan standar mutu dan dapat diterima oleh pasar.

\section{METODE PENELITIAN}

\subsection{Metode Kerja}

Metode penelitian ini adalah penelitian survey deskriptif yaitu penelitian yang bertujuan untuk menggambarkan parameter- parameter penting yang terdapat dalam bubuk kakao yang beredar di makassar. Sumber data yang digunakan dalam penelitian ini adalah data primer yang diperoleh dari hasil analisa kadar air, kadar lemak, kadar kehalusan, dan cemaran logam dengan menggunakan metode uji SNI 2323: 2008.

\subsection{Teknik Pengumpulan data}

Kakao bubuk yang telah dipilih sebanyak 15 sample sebagai bahan uji penelitian dengan pengumpulan data dari tahun 2016 sampai tahun 2017 dimana data yang diperoleh dikumpulkan dan dianalisis secara deskriptif berdasarkan parameter mutu sesuai dengan SNI Kakao bubuk yaitu SNI 3747:2013.

\section{HASIL DAN PEMBAHASAN}

Hasil uji kadar air dalam kakao bubuk dapat dilihat pada tabel 1 . 
Tabel 1. Hasil Uji kadar air.

\begin{tabular}{cccc}
\hline No & $\begin{array}{c}\text { Sample Kakao } \\
\text { Bubuk }\end{array}$ & Satuan & Hasil \\
\hline 1 & BK 1 & $\%$ & 4.84 \\
2 & BK 2 & $\%$ & 5.00 \\
3 & BK 3 & $\%$ & $\mathbf{5 . 2 0}$ \\
4 & BK 4 & $\%$ & 3.66 \\
5 & BK 5 & $\%$ & 3.69 \\
6 & BK 6 & $\%$ & 3.92 \\
7 & BK 7 & $\%$ & 4.40 \\
8 & BK 8 & $\%$ & 4.30 \\
9 & BK 9 & $\%$ & 4.18 \\
10 & BK 10 & $\%$ & 4.80 \\
11 & BK 11 & $\%$ & 3.80 \\
12 & BK 12 & $\%$ & 4.10 \\
13 & BK 13 & $\%$ & 3.61 \\
14 & BK 14 & $\%$ & 4.42 \\
15 & BK 15 & $\%$ & $\mathbf{5 . 1 6}$ \\
\hline
\end{tabular}

Dari tabel 1. diatas menunjukkan bahwa ada 8 sampel kakao bubuk memenuhi standar baku mutu dan 2 sampel yang hasil kadar airnya tidak memenuhi standar SNI kakao bubuk, dimana standar yang dipersyaratkan yaitu maksimal $5 \%$. Kadar air bubuk cokelat yang dihasilkan rata-rata berkisar antara 3,61 -5,20\%. Berdasarkan data dari 15 sample bubuk kakao(Tabel 1. ) ada 2 sample bubuk kakao yang tidak memenuhi standar mutu SNI uaitu bubuk kakao BK3 dan BK15. Hal ini disebabkan karena kemungkinan faktor terfermentasi dan tidak terfermentasi dari pengolahan biji kakao. Hal ini menyebabkan selama berlangsungnya waktu fermentasi terjadi peningkatan kadar air dalam biji cokelat (Rizkyansyah,2007).

Kadar air merupakan banyaknya air yang terkandung dalam bahan yang dinyatkan dalam persen. Kadar air merupakan karakteristik yang sangat penting pada bahan pangan, karena air dapat mempengaruhi penampakan, tekstur, dan cita rasa pada bahan pangan. Kadar air yang tinggi dapat mengakibatkan mudahnya bakteri, kapang, dan khamir untuk berkembang biak, sehingga akan terjadi perubahan pada bahan pangan(Winarno, 1997).

Salah satu penyebab tingginya kadar air pada bubuk kakao atau kakao bubuk karena proses penyimpanan dapat mempengaruhi kenaikan kadar air. Bubuk kakao yang disimpan pada kelembaban tinggi (RH diatas $75 \%$ ) atau karena terjadinya penumpukan uap air. Oleh karena itu semua produk olahan cokelat dapat disimpan diruang penyimpanan yang ideal, kering, sirkulasi udara yang baik, terlindungi dari cahaya dan suhu kelembaban 55-65 \% (Elvira Syamsir, 2011). Hasil uji kadar lemak dapat dilihat pada tabel 2.

Tabel 2. Hasil Uji kadar Lemak

\begin{tabular}{cccc}
\hline No & $\begin{array}{c}\text { Sample Kakao } \\
\text { Bubuk }\end{array}$ & Satuan & Hasil \\
\hline 1 & BK 1 & $\%$ & 27.73 \\
2 & BK 2 & $\%$ & 16.17 \\
3 & BK 3 & $\%$ & 25.84 \\
4 & BK 4 & $\%$ & 27.65 \\
5 & BK 5 & $\%$ & 14.82 \\
6 & BK 6 & $\%$ & 14.01 \\
7 & BK 7 & $\%$ & 12.14 \\
8 & BK 8 & $\%$ & 11.32 \\
9 & BK 9 & $\%$ & 12.84 \\
10 & BK 10 & $\%$ & 12.56 \\
11 & BK 11 & $\%$ & 13.26 \\
12 & BK 12 & $\%$ & 16.24 \\
13 & BK 13 & $\%$ & 12.18 \\
14 & BK 14 & $\%$ & 13.55 \\
15 & BK 15 & $\%$ & 18.21 \\
\hline
\end{tabular}

Dari tabel 2. Diatas menunjukkan bahwa kadar lemak dari 15 sampel yang ada di pasaran kota Makassar rata -rata sudah memenuhi standar baku mutu yang dipersyaratkan SNI kakao bubuk yaitu min $10 \%$. Kadar lemak pada suatu kakao bubuk juga berpengaruh terhadap mutu dari bubuk kakao . Pada proses pengolahan bubuk kakao sebagian lemak kakao yang ada pada pasta coklat harus dipisahkan. Kadar lemak didalam bubuk kakao berkisar antara 20-20\% bubuk kakao berkadar lemak tinggi biasanya memiliki warna lebih gelap dengan flavor yang lebih ringan dan umunya faktor suhu sangat mempengaruhi rendemen lemak sehingga pengepresan lemak berpengaruh terhadap kadar lemak pada kakao bubuk yang dihasilkan (Melia Ariyanti, 2017). Hasil kadar kehalusan dapat dilihat pada tabel 3. 
Tabel 3. Hasil Uji kadar Kehalusan

\begin{tabular}{cccc}
\hline No & $\begin{array}{c}\text { Sample Kakao } \\
\text { Bubuk }\end{array}$ & Satuan & Hasil \\
\hline 1 & BK 1 & $\%$ & 99,5 \\
2 & BK 2 & $\%$ & 97,8 \\
3 & BK 3 & $\%$ & 96,6 \\
4 & BK 4 & $\%$ & 96,8 \\
5 & BK 5 & $\%$ & 99,8 \\
6 & BK 6 & $\%$ & 99,7 \\
7 & BK 7 & $\%$ & $\mathbf{9 9 , 3}$ \\
8 & BK 8 & $\%$ & 99,6 \\
9 & BK 9 & $\%$ & 99,9 \\
10 & BK 10 & $\%$ & 99,7 \\
11 & BK 11 & $\%$ & $\mathbf{9 8 , 9}$ \\
12 & BK 12 & $\%$ & $\mathbf{9 8 , 9}$ \\
13 & BK 13 & $\%$ & 99,5 \\
14 & BK 14 & $\%$ & $\mathbf{9 9 . 4}$ \\
15 & BK 15 & $\%$ & 99,5 \\
\hline
\end{tabular}

Dari tabel 3. Menunjukkan bahwa kadar kehalusan dari 15 sampel bubuk kakao, terdapat 4 sampel kakao bubuk yang tidak memenuhi standar mutu SNI kakao bubuk yaitu BK 7, BK 11,BK 12, BK 14. Hal ini disebabkan karena kemungkinan pada saat proses pengayakan dan pengolahan kakao bubuk kurang optimal. Hasil uji kadar cemaran logam pada kakao bubuk dapat dilihat pada tabel 4 .

Tabel 4. Hasil Uji kadar Cemaran Logam.

\begin{tabular}{ccccccc}
\hline \multirow{2}{*}{ No } & \multirow{2}{*}{ Industri } & \multicolumn{5}{c}{ Hasil (mg/kg) } \\
\hline & & $\mathrm{Pb}$ & $\mathrm{Cd}$ & $\mathrm{Sn}$ & $\mathrm{As}$ & $\mathrm{Hg}$ \\
\cline { 3 - 7 } 1 & BK 1 & 2.1990 & 0.2371 & 5.3912 & $<0.05$ & $<0.005$ \\
2 & BK 2 & 0.6514 & 0.2681 & 5.8721 & $<0.05$ & $<0.005$ \\
3 & BK 3 & 0.1802 & 0.1900 & 4.7266 & $<0.05$ & $<0.005$ \\
4 & BK 4 & 0.6272 & 0.1434 & 2.0167 & $<0.05$ & $<0.005$ \\
5 & BK 5 & 0.1811 & 0.1656 & 3.1621 & $<0.05$ & $<0.005$ \\
6 & BK 6 & 0.2285 & 0.7326 & 1.2661 & $<0.05$ & $<0.005$ \\
7 & BK 7 & 1.1308 & 0.6213 & 1.2871 & $<0.05$ & $<0.005$ \\
8 & BK 8 & 1.2514 & 0.2286 & 1.2641 & $<0.05$ & $<0.005$ \\
9 & BK 9 & 0.4378 & 0.0727 & 302651 & $<0.05$ & $<0.005$ \\
10 & BK 10 & 0.2170 & 0.0431 & 5.4107 & $<0.05$ & $<0.005$ \\
11 & BK 11 & 0.2414 & 0.0870 & 502671 & $<0.05$ & $<0.005$ \\
12 & BK 12 & 0.2618 & 0.4509 & 5.2761 & $<0.05$ & $<0.005$ \\
13 & BK 13 & 1.2617 & 0.7126 & 4.3216 & $<0.05$ & $<0.005$ \\
14 & BK 14 & 2.1405 & 0.3414 & 2.4081 & $<0.05$ & $<0.005$ \\
15 & BK 15 & 2.0507 & 0.2617 & 2.4121 & $<0.05$ & $<0.005$ \\
\hline
\end{tabular}

Cemaran logam pada bahan pangan terutama untuk produk kakao merupakan salah satu penyebab food borndisease. Logam berat dapat pula mencemari makanan melalui alat-ala yang digunakan untuk mengolah dan menyajikan makanan. Menurut Gayatri (1999). Menyatakan logam akan terakumulasi pada jaringan tubuh dan dapat menimbulkan keracunan pad manusia, hewan dan tumbuhan apabila melebihi batas toleransi. Pada proses pembuatan kakao bubuk pada umumnya menggunakan peraltan dan mesin yang terbuat dari logam. Yang mana selama proses mengalami gesekan komponen terhadap kakao bubuk yang dihasilkan.

\section{KESIMPULAN}

Berdasarkan hasil pengujian kadar air, kadar lemak, kadar kehalusan dan hasil analisa cemaran logam pada kakao bubuk yang ada dipasaran kota Makassar dapat disimpulkan bahwa dari 15 sample yang ada, rata - rata kadar lemak 11 sampai $27 \%$ dan cemaran logam sudah memenuhi standar SNI tetapi pada kadar air ratarata berkisar 3 sampai $5 \%$, namun masih terdapat 2 sample dengan kadar air yang melebihi standar mutu SNI kakao Bubuk, akan tetapi bila dilihat dari semua data yang ada masih dapat dikatakan bahwa rata-rata kakao bubuk yang ada dikota Makassar masih dalam taraf kualitas yang baik.

\section{DAFTAR PUSTAKA}

Abraham, (1982). Manufacture of Chocolate the planters:58(657): 256.259

Beckett, (1999). Industrial Chocolate Manufacture.crd.use Blackwell.ltd.Oxford

Badan Standardisasi Nasional. (2008). Biji Kakao. SNI Nomor 2323:2008. BSN . Jakarta.

Badan Standardisasi Nasional. (1998). Metode Uji Kakao Bubuk . SNI Nomor 19-0428-1998. BSN . Jakarta.

Elvira Syamsir, (2011). Ilmu pangan. Blog .spot. personal.Bogor.

Gayatri, (1994).Bunga Rampai Residu Pestisida dan Alternatif.PAN. Indonesia, Jakarta.

Melia Ariyanti. (2017) Pengaruh Pengepresan Berulang Terhadap Kadar Lemak Kakao Bubuk. Jurnal JRTI .vol 7. 8- 32.

Majalah Indonesia, (2017). Sehat Dengan Bubuk Cokelat. JAKARTA-KAKAO. 
INDONESIA. https//www.kakaoindonesia.com/index. Php/news-feed/369sehat-dengan-bubu-cokelat. Diakses tgl 26 Februari 2018.

Mulato.Destira.Yanasa. Anfira. (2005). Pengolahan produk Primer dan sekunder kakao. Pusat Penelitian kopi dan kakao Indonesia .Jember.
Rizkyansyah. (2007). Teknik Pengolahan Biji Kakao. Pustaka Ilmu. WordPress. Jakarta.

Susanti, (2012). Budidaya dan proses pengolahan cokelat, skripsi Susanti.pdf. Universitas Semarang. Fakultas Pertanian. Semarang. Winarno, (1997). Kimia Pangan dan Gizi. Jakarta. 